\title{
Bu open Body mass index and perioperative complications after oesophagectomy for adenocarcinoma: a systematic database review
}

\author{
Marcovalerio Melis, ${ }^{1}$ Jill Weber, ${ }^{2}$ Ravi Shridhar, ${ }^{2}$ Sarah Hoffe, ${ }^{2}$ \\ Khaldoun Almhanna, ${ }^{2}$ Richard C Karl, ${ }^{2}$ Kenneth L Meredith ${ }^{2}$
}

To cite: Melis M, Weber J, Shridhar R, et al. Body mass index and perioperative complications after oesophagectomy for adenocarcinoma: a systematic database review. BMJ Open 2013;3:e001336. doi:10.1136/bmjopen-2012001336

- Prepublication history for this paper are available online. To view these files please visit the journal online (http://dx.doi.org/10.1136/ bmjopen-2012-001336).

Received 18 May 2012 Revised 25 July 2012 Accepted 6 August 2012

This final article is available for use under the terms of the Creative Commons Attribution Non-Commercial 2.0 Licence; see http://bmjopen.bmj.com

${ }^{1}$ Department of Surgery, New York University Medical School, New York, New York, USA

${ }^{2}$ Department of Gastrointestinal Oncology, Moffitt Cancer Center, Tampa, Florida, USA

Correspondence to Dr Kenneth Meredith; kenneth.meredith@moffitt. org
ABSTRACT

Objective: Given the increasing rate of obesity, the effects of excessive body weight on surgical outcomes constitute a relevant quality of care concern. Our aim was to determine the relationship between preoperative body mass index (BMI) on perioperative complications after oesophagectomy for adenocarcinoma of the oesophagus.

Design: Retrospective database review.

Setting: Single institution high volume oncological tertiary care referral centre.

Participants: From our comprehensive oesophageal cancer database consisting of 709 patients, we stratified patients according to BMI: 155 normal-weight (BMI 20-24), 198 overweight (BMI 25-29) and 187 obese (BMI $\geq 30$ ) patients.

Interventions: All patients underwent oesophagectomy for cancer.

Primary and secondary outcome measures:

Incidences of preoperative risk factors and perioperative complications in each group were analysed.

Results: The patient cohort consisted of 474 men and 66 women with a mean age of 64.3 years (2886). They were similar in terms of demographics and comorbidities, with the exception of a younger age (65.2 vs 65.4 vs 62.5 years, $p=0.0094$ ), and a higher incidence of diabetes ( $9.1 \%$ vs $13.2 \%$ vs $22.7 \%$, $p=0.001)$, hiatal hernia $(16.8 \%$ vs $17.8 \%$ vs $28.8 \%$, $\mathrm{p}=0.009)$ and Barrett oesophagus (24.7\% vs $25.4 \%$ vs $36.2 \%, p=0.025)$ for obese patients. The type of surgery performed, overall blood loss, extent of lymphadenectomy, $\mathrm{R} 0$ resections and complications were not influenced by BMI on univariate and multivariate analysis.

Conclusions: In our experience, patients with an elevated BMI and oesophageal adenocarcinoma do not experience an increase in morbidity and mortality after oesophagectomy as stated in previous reports, when performed at a high volume centre. Additionally, BMI did not affect the quality of oncological resection as determined by number of harvested lymph-nodes and rates of $\mathrm{RO}$ resections.

Trial Registration: MCC 15030, IRB 105286.

\section{ARTICLE SUMMARY}

Article focus

- Evaluate the perioperative outcomes in patients who undergo oesophagectomy.

- Identify the impact of an elevated body mass index (BMI) on patients with adenocarcinoma of the oesophagus who undergo surgical resection.

Key messages

- Patients with adenocarcinoma of the oesophagus who have an elevated BMI do not experience increased postoperative complications.

- The quality of oncological resection was also not affected by an elevated BMI.

Strengths and limitations of this study

- This is a retrospective review of a comprehensive esophageal cancer database.

\section{INTRODUCTION}

The well-documented obesity epidemic in the USA has prompted an increased focus on its role as a risk factor for the development of adverse health conditions such as diabetes, hypertension, coronary artery disease and cancer. ${ }^{1}{ }^{2}$ New and ongoing research efforts are reporting an association between obesity and pathophysiological changes in the body such as impairment of cardiac, pulmonary and immunological functions. Many surgeons believe that there are increased technical challenges and postoperative complications associated with operations on patients with a body mass index (BMI) above $30 .^{2}$ However, this perception is not supported by the existing literature and controversy remains about the relationship between obesity and outcomes after any type of elective surgery. ${ }^{3}$ In particular, little information is currently available about the influence of obesity on outcomes after surgery of the alimentary tract, such as oesophagectomy. 
Surgical resection is the standard of care for early stage oesophageal cancers and part of a multimodality treatment regimen for advanced oesophageal cancers. Therefore, it is important to evaluate morbidity of oesophagectomy in obese patients. The aim of this study is to determine the effects of preoperative BMI on outcomes after oesophagectomy for adenocarcinoma.

\section{METHODS}

All aspects of this study were approved from our institutional review board. A query was performed from our comprehensive oesophageal cancer database consisting of all patients who underwent an oesophagectomy for adenocarcinoma at the Moffitt Cancer Center between June 1994 and January 2011. Retrospective chart reviews were performed solely by experienced clinicians and recorded on standardised abstraction forms. Data were entered into a secure web-based data entry system and uploaded into an Access database by a data analyst. Ambiguities in any data points were discussed by committee, researched, reviewed and corrected. Data entry quality was monitored with $33 \%$ of all cases being re-reviewed for accuracy. The database currently contains 709 patients. The data collected for the database include patient demographics, preoperative symptoms, Charlson comorbidities index, ${ }^{4}$ risk factor history, family history, tumour stage and histopathological features, perioperative events and complications. Patients were excluded if they did not have a cancer diagnosis, had a diagnosis of squamous cell carcinoma or in which data were missing.

Patients referred to our institution with oesophageal cancer or dysplasia are evaluated by a multidisciplinary oesophageal cancer team composed of surgical oncologists, gastroenterologists, medical oncologists, radiation oncologists and gastrointestinal pathologists. Clinical staging includes, primarily, an oesophagogastroduodenoscopy with endoscopic ultrasound and a CT of the chest and abdomen. A $\left[{ }^{18} \mathrm{~F}\right]$-fluoro-2-deoxy-D-glucose positron emission tomography is performed to evaluate for systemic metastasis. This has been standard practice at our institution since 2003. Treatment is then customised according to stage and pathological features as well as to the patient's conditions and personal preferences. Most commonly, a platinum-based neoadjuvant chemo-radiation therapy regimen followed by oesophagectomy is recommended for resectable, non-metastatic oesophageal cancer with stage greater than T1N0M0 in patients with ECOG performance status $0-1 .^{5}$ Transthoracic, transhiatal and minimally-invasive esophagectomies (MIE) are routinely performed. MIEs were performed via a transhiatal, transthoracic or robotic (Ivor Lewis) approach. The open operations were most often performed via transthoracic (Ivor Lewis) technique. The choice of surgical technique is based on tumour location and stage as well as the surgeon's and patient's preference. Select patients underwent MIE, but the decision as to surgery type was made irrespective of BMI and uniformly on an individual surgeon's practice and expertise.
The current study was restricted to all patients with oesophageal adenocarcinoma who completed an oesophagectomy and had height and weight data recorded prior to surgery. BMI was calculated according to a standardised definition as weight in kilograms divided by height in metres squared. We defined obesity according to the WHO's definition, as BMI equal or greater than $30 \mathrm{~kg} / \mathrm{m}^{2}{ }^{6}$ For this study, we stratified BMI into three categories: normal-weight (BMI 18.5-25 kg/m ${ }^{2}$ ), overweight (BMI $25-30 \mathrm{~kg} / \mathrm{m}^{2}$ ) and obese (BMI $>30 \mathrm{~kg} / \mathrm{m}^{2}$ ) patients. Patients with malnutrition (BMI of $<18.5 \mathrm{~kg} / \mathrm{m}^{2}$, $\mathrm{n}=5$ ) were excluded.

All complications from surgery to discharge from the hospital were investigated. Respiratory failure was defined as the requirement for mechanical ventilation more than $24 \mathrm{~h}$ after surgery. Extended ICU was defined as more than 2 days in the ICU postoesophagectomy. The diagnosis of pneumonia required positive sputum cultures or clear clinical and radiographic evidence of consolidation. Major pulmonary complications for the purpose of this analysis were defined as pneumonia, pleural effusion (as evidence on chest x-ray), pulmonary embolus (as diagnosed by VQ scan or spiral CT of the chest) and respiratory failure. Anastomotic leak was diagnosed by evidence of radiographic imaging via upper gastrointestinal series (UGI) or CT scan. Mortality was defined as any death within 30 days of oesophagectomy.

Univariate statistical analysis between preoperative risk factors and perioperative complications and BMI were performed using the $\chi^{2}$ or Fisher's exact test, as appropriate. A summary variable of any complication was defined as yes if one or more complications were documented compared to no documented complications from a set of complications used for this study. Mean differences between preoperative risk factors and perioperative complications and BMI were examined for continuous data using ANOVA. All statistical tests performed were two-sided and declared at the $5 \%$ significance level. The multivariate analysis estimated the association between outcomes (mortality and any postoperative complication) and BMI controlling for age, diabetes, pathological stage, neoadjuvant therapy, type of surgery, intraoperative blood loss and operative time using Cox Proportional-Hazards Regression modelling. Statistical analyses were performed with STATA IC (STATA Statistical Software, Release 10.0; Strata Corp, College Station, Texas, USA).

\section{RESULTS}

\section{Patient demographics}

We identified $540(76.2 \%)$ patients from our oesophageal database who met our inclusion criteria. Among them 155 (28.7\%) were normal-weight, 198 (36.7\%) were overweight and $187(34.6 \%)$ were obese. Among the obese patients, the majority $118(63.1 \%)$ had class I obesity (BMI $30-34 \mathrm{~kg} / \mathrm{m}^{2}$ ); 49 patients $(26.2 \%$ ) had class II (BMI $35-39 \mathrm{~kg} / \mathrm{m}^{2}$ ) and only $20(10.7 \%)$ had class III obesity (BMI $>40 \mathrm{~kg} / \mathrm{m}^{2}$ ). 
Table 1 Demographics, comorbidities and surgical and pathological variables stratified by body mass index (BMI) in 540 patients undergoing oesophagectomy

\begin{tabular}{|c|c|c|c|c|}
\hline & $\begin{array}{l}\text { Normal weight } \\
\text { BMI 18.5-25 } \\
\mathrm{N}=155, \mathrm{~N}(\%)\end{array}$ & $\begin{array}{l}\text { Overweight } \\
\text { BMI 25-30 } \\
\mathrm{N}=198, \mathrm{~N}(\%)\end{array}$ & $\begin{array}{l}\text { Obese } B M I>30 \\
N=187, N(\%)\end{array}$ & p Value \\
\hline \multicolumn{5}{|l|}{ Clinical/pathological characteristics } \\
\hline Male & $126(81.3)$ & $181(91.4)$ & $167(89.3)$ & 0.012 \\
\hline Age (years; mean $\pm S D$ ) & $65.2 \pm 9.99$ & $65.4 \pm 10.4$ & $62.5 \pm 10.2$ & 0.0094 \\
\hline \multicolumn{5}{|l|}{ Medical history } \\
\hline Coronary artery disease or $\mathrm{Ml}$ & $33(21.3)$ & $48(24.2)$ & $43(23.0)$ & 0.8 \\
\hline Congestive heart failure & $3(2.0)$ & $5(2.5)$ & $5(2.7)$ & 0.9 \\
\hline Peripheral vascular disease & $11(7.1)$ & $15(7.6)$ & $6(3.2)$ & 0.1 \\
\hline Cerebrovascular disease & $6(3.9)$ & $11(5.6)$ & $12(6.4)$ & 0.6 \\
\hline Mild/moderate COPD & $24(15.6)$ & $23(11.7)$ & $23(12.4)$ & 0.5 \\
\hline Diabetes & $14(9.1)$ & 26 (13.2) & $42(22.7)$ & 0.001 \\
\hline Renal disease & $4(2.6)$ & $3(1.5)$ & $1(0.5)$ & 0.3 \\
\hline Liver disease & $1(0.7)$ & $4(2.0)$ & $1(0.5)$ & 0.4 \\
\hline Hiatal hernia & $26(16.8)$ & $35(17.8)$ & $53(28.8)$ & 0.009 \\
\hline Gastroesophageal reflux disease & $72(46.5)$ & $93(47.0)$ & $103(55.1)$ & 0.2 \\
\hline Barrett's oesophagus & $38(24.7)$ & $50(25.4)$ & 67 (36.2) & 0.025 \\
\hline Alcohol history & $123(83.1)$ & $154(79.4)$ & $146(79.8)$ & 0.7 \\
\hline Smoking history & $102(68.5)$ & $129(67.9)$ & $133(72.7)$ & 0.6 \\
\hline \multicolumn{5}{|l|}{ ASA score } \\
\hline 1 & $1(0.8)$ & $2(1.2)$ & $1(0.6)$ & 0.1 \\
\hline 2 & 67 (51.9) & $97(58.8)$ & 77 (48.7) & \\
\hline 3 & $61(47.3)$ & $63(38.2)$ & $80(50.6)$ & \\
\hline 4 & 0 & $3(1.8)$ & 0 & \\
\hline \multicolumn{5}{|l|}{ Preoperative stage } \\
\hline $0-1$ & $18(14.4)$ & $25(16.1)$ & $38(24.2)$ & 0.07 \\
\hline II-IV & 107 (85.6) & 130 (83.9) & 119 (75.8) & \\
\hline \multicolumn{5}{|l|}{ Treatment details } \\
\hline Neoadjuvant therapy & $110(71.0)$ & $119(60.4)$ & $95(50.8)$ & 0.45 \\
\hline \multicolumn{5}{|l|}{ Type of surgery } \\
\hline Transthoracic & $102(65.8)$ & $144(72.7)$ & $127(68.3)$ & 0.6 \\
\hline Transhiatal & $15(9.7)$ & $19(9.6)$ & $15(8.0)$ & \\
\hline Minimally invasive transthoracic & $20(12.9)$ & $21(10.6)$ & $21(11.3)$ & \\
\hline Minimally invasive transhiatal & $18(11.6)$ & $14(7.1)$ & $23(12.4)$ & \\
\hline Operative time (minutes, mean $\pm S D$ ) & $272 \pm 91$ & $273 \pm 69$ & $288 \pm 94$ & 0.2 \\
\hline \multicolumn{5}{|l|}{ Quality of resection } \\
\hline Ro (no residual disease) & $150(96.8)$ & $186(94.4)$ & $174(93.6)$ & 0.8 \\
\hline R1 (residual microscopic disease) & $3(1.9)$ & $7(3.6)$ & $8(4.3)$ & \\
\hline R2 (residual gross disease) & $2(1.3)$ & $4(2.0)$ & $4(2.2)$ & \\
\hline $\mathrm{EBL}(\mathrm{ml})$ & $236 \pm 219$ & $245 \pm 239$ & $276 \pm 231$ & 0.3 \\
\hline LOS & $11.9 \pm 6.7$ & $12.4 \pm 7.8$ & $13.9 \pm 10.5$ & 0.07 \\
\hline
\end{tabular}

COPD, chronic obstructive pulmonary disease; EBL, estimated blood loss; LOS, length of stay.

Table 1 describes the demographics, comorbidities, surgical and pathological characteristics of our patient population stratified by BMI. There were 474 men and 66 women with a mean age of 64.3 years (28-86 years) at the time of surgery. There was a statistically significant association between younger age (65.2 vs 65.4 vs 62.5 years, $\mathrm{p}=0.009)$, diabetes $(9.1 \%$ vs $13.2 \%$ vs $22.7 \%$, $\mathrm{p}=0.001)$, hiatal hernia $(16.8 \%$ vs $17.8 \%$ vs $28.8 \%$, $\mathrm{p}=0.009)$ and Barrett oesophagus $(24.7 \%$ vs $25.4 \%$ vs $36.2 \%, \mathrm{p}=0.025)$ for obese patients. There were no statistical differences between groups in frequency of coronary artery disease or myocardial infarction (MI) $(\mathrm{p}=0.8)$, peripheral vascular disease $(p=0.1)$ and cerebrovascular disease $(p=0.6)$, congestive heart disease $(p=0.9)$, chronic obstructive pulmonary disease $(p=0.5)$, renal insufficiency $(p=0.3)$, ASA score $(p=0.1)$, history of smoking $(\mathrm{p}=0.6)$ or alcohol use $(\mathrm{p}=0.7)$. Gastroesophageal reflux ( $46.5 \%$ vs $47.0 \%$ vs $55.1 \%$ ) was slightly more frequent in obese patients without reaching significance $(\mathrm{p}=0.2)$.

\section{Pathological characteristics}

There was no significant difference in the distribution of stage among normal-weight, overweight and obese patients $(\mathrm{p}=0.07)$. A smaller percentage of obese patients received neoadjuvant therapy $(71.0 \%$ vs $60.4 \%$ 
vs $50.8 \%)$. However, when preoperative stage was stratified by administration of neoadjuvant therapy, this failed to reach significance when compared to overweight and normal-weight patients $(p=0.45)$. We also examined the impact of BMI on quality of resection and we found no significant differences across groups in rates of R0, R1 or $\mathrm{R} 2$ resections $(\mathrm{p}=0.8)$. Additionally, there were no differences in the number of nodes harvested between groups (mean 10.8 $\pm 6.1,11.2 \pm 5.5$ and 10.6 $\pm 7.8 ; \mathrm{p}=0.72$ ).

\section{Operative outcomes}

The type of surgery and mean estimated blood loss in millilitres for normal-weight, overweight and obese patients (236 vs 245 vs 276 ) did not differ among groups ( $p=0.6$ and 0.3 , respectively). The mean operative time for normal-weight patients was $272 \mathrm{~min}$ compared to $273 \mathrm{~min}$ in overweight and $288 \mathrm{~min}$ in obese patients $(\mathrm{p}=0.2)$. There were no significant differences observed in the frequency of individual postoperative complications (table 2): MI $(\mathrm{p}=0.5)$, atrial fibrillation $(\mathrm{p}=1.0)$, other cardiac arrhythmias $(\mathrm{p}=0.4)$, respiratory failure $(\mathrm{p}=0.9)$, pneumonia $(\mathrm{p}=0.3)$, intraoperative injury $(\mathrm{p}=0.5)$, extended ICU $(\mathrm{p}=0.8)$, anastomotic leak or stricture (respectively, $\mathrm{p}=0.3$ and $\mathrm{p}=0.8$ ), deep venous thrombosis $(\mathrm{p}=0.7)$, pulmonary embolus $(\mathrm{p}=0.8)$, pleural effusion $(\mathrm{p}=0.8)$, surgical site infections $(\mathrm{p}=0.4)$ or reoperations $(p=0.9)$. These results were maintained when examining the frequency of any complications across BMI groups $(p=0.3)$. The mean length of hospitalisation in the normal-weight patient population was 11.9 days compared to 12.4 days in overweight and 13.9 days in obese $(\mathrm{p}=0.07)$. The 30 -day mortality was $1.9 \%$ which was not statistically significant among groups $(\mathrm{p}=0.7)$. We then performed a separate analysis investigating the outcomes of the super obese patients who underwent oesophagectomy (BMI $>35$ and BMI >40) (table 3). All analyses confirmed no increased risk of morbidity or mortality in both groups when compared to their lower BMI counterparts.

Four separate multivariate logistic regression analyses of three frequently occurring complications (surgical site infection, pneumonia and anastomotic leak) and the onset of any postoperative complication are presented in table 4 . In the multivariate analyses, there were no statistically significant associations between overweight and obesity and postoperative complications controlling for age, diabetes, stage, neoadjuvant therapy, type of surgery, intraoperative blood loss and operative time. Obese/overweight patients were 0.4 times less likely to suffer from anastomotic leak compared to normal-weight patients; however, this failed to reach statistical significance $(\mathrm{p}=0.051)$.

We addressed the possibility of a confounding volume and temporal relationship between obese patients and operative outcomes. Patients were stratified according to timing of their operation: time strata (TS) 1: 1995-2000, TS 2: 2001-2006 and TS 3: 2007-present. There was an equal distribution of obese patients identified in each time strata $(20.3 \%, 45.4 \%$ and $34.2 \%$, respectively, $\mathrm{p}=0.943$ ). We did not identify an association between increasing BMI and any complication across each time strata (TS $1(\mathrm{p}=0.5)$, TS $2(\mathrm{p}=0.6)$ and TS $3(\mathrm{p}=0.1))$. We also compared all TSs to identify any potential differences in complications by BMI (normal weight, overweight and obese). No statistical differences were noted across TS ( $\mathrm{p}=0.8, \mathrm{p}=0.5$ and $\mathrm{p}=0.06$ ), suggesting that our results of BMI and outcome were not confounded by

Table 2 Univariate analysis results of early and delayed postoperative complications and mortality stratified by body mass index (BMI) status

\begin{tabular}{|c|c|c|c|c|}
\hline $\begin{array}{l}\text { Surgical } \\
\text { complications }\end{array}$ & $\begin{array}{l}\text { Normal weight BMI 18.5-25 } \\
\mathrm{N}=155, \mathrm{~N}(\%)\end{array}$ & $\begin{array}{l}\text { Overweight BMI 25-30 } \\
\mathrm{N}=198, \mathrm{~N}(\%)\end{array}$ & $\begin{array}{l}\text { Obese } \mathrm{BMI}>30 \\
\mathrm{~N}=187, \mathrm{~N}(\%)\end{array}$ & p Value \\
\hline Intraoperative injury & $1(0.7)$ & 0 & $1(0.5)$ & 0.5 \\
\hline $\mathrm{MI}$ & $3(1.9)$ & $1(0.5)$ & $2(1.0)$ & 0.5 \\
\hline Atrial fibrillation & $1(0.7)$ & $1(0.5)$ & $1(0.5)$ & 1.0 \\
\hline Cardiac arrhythmia & $16(10.7)$ & 30 (15.4) & 23 (12.4) & 0.4 \\
\hline Reoperation & $5(3.2)$ & $8(4.0)$ & $6(3.2)$ & 0.9 \\
\hline $\begin{array}{l}\text { Prolonged ICU stay } \\
(>2 \text { days })\end{array}$ & $16(10.3)$ & $25(12.6)$ & $20(10.7)$ & 0.8 \\
\hline Surgical site infection & $7(4.7)$ & $14(7.2)$ & $16(8.6)$ & 0.4 \\
\hline Pneumonia & $28(18.1)$ & 25 (12.6) & $32(17.1)$ & 0.3 \\
\hline Pleural effusion & $8(5.3)$ & $8(4.1)$ & $7(3.8)$ & 0.8 \\
\hline Respiratory failure & $10(6.7)$ & $12(6.2)$ & $14(7.6)$ & 0.9 \\
\hline Anastomotic leak & $13(8.7)$ & $9(4.6)$ & $15(8.1)$ & 0.3 \\
\hline Anastomotic stricture & $16(10.7)$ & $25(12.8)$ & $22(11.9)$ & 0.8 \\
\hline $\begin{array}{l}\text { Deep venous } \\
\text { thrombosis }\end{array}$ & $3(2.0)$ & $2(1.0)$ & $4(2.2)$ & 0.7 \\
\hline Pulmonary embolus & $3(2.0)$ & $5(2.6)$ & $6(3.2)$ & 0.8 \\
\hline Any complications* & 65 (41.9) & 97 (48.9) & $91(48.7)$ & 0.3 \\
\hline Mortality (<30 days) & $2(1.3)$ & $3(1.5)$ & $5(2.7)$ & 0.7 \\
\hline
\end{tabular}

*Defined as the presence of one or more of the complications listed above in a single patient.

ICU, intensive care unit; MI, myocardial infarction. 
Table 3 Univariate analysis results of early and delayed postoperative complications and mortality stratified by super obesity

\begin{tabular}{|c|c|c|c|c|}
\hline Surgical complications & BMI >35 N=69, N (\%) & p Value & $\mathrm{BMI}>40 \mathrm{~N}=20, \mathrm{~N}(\%)$ & p Value \\
\hline Intraoperative injury & 0 & 1.0 & 0 & 1.0 \\
\hline $\mathrm{Ml}$ & $1(1.5)$ & 0.6 & 0 & 1.0 \\
\hline Atrial fibrillation & 0 & 1.0 & 0 & 1.0 \\
\hline Cardiac arrhythmia & 9 (13.2) & 1.0 & $3(15.8)$ & 0.7 \\
\hline Reoperation & $1(1.5)$ & 0.5 & $1(5.0)$ & 0.6 \\
\hline Prolonged ICU stay & $8(11.8)$ & 0.8 & $2(10.5)$ & 1.0 \\
\hline Surgical site infection & 7 (10.3) & 0.3 & $2(10.5)$ & 0.4 \\
\hline Pneumonia & $13(18.8)$ & 0.5 & $2(10.0)$ & 0.8 \\
\hline Pleural effusion & $1(1.5)$ & 0.3 & 0 & 1.0 \\
\hline Respiratory failure & $5(7.4)$ & 0.8 & $2(10.5)$ & 0.4 \\
\hline Anastomotic leak & $4(5.9)$ & 0.8 & 0 & 0.4 \\
\hline Anastomotic stricture & $9(13.2)$ & 0.7 & $1(5.3)$ & 0.7 \\
\hline Deep venous thrombosis & $1(1.5)$ & 1.0 & 0 & 1.0 \\
\hline Pulmonary embolus & $2(3.0)$ & 0.7 & $1(5.3)$ & 0.4 \\
\hline Any complications* & 31 (44.9) & 0.7 & $5(25.0)$ & 0.05 \\
\hline Mortality & $3(4.4)$ & 0.1 & 0 & 1.0 \\
\hline
\end{tabular}

${ }^{*}$ Defined as the presence of one or more of the complications listed above in a single patient.

ICU, intensive care unit; MI, myocardial infarction.

more oesophagectomies performed in obese patients later in our experience.

\section{DISCUSSION}

It is often assumed that obese patients have a higher risk of surgical complications compared to patients who are within their normal weight range. ${ }^{3}$ However, data assessing the effect of obesity on outcomes of various surgical procedures have provided inconsistent results with the exception of a consistent increased risk for minor surgical site infections among obese patients. ${ }^{3-13}$ Research examining surgical outcomes among obese patients has primarily focused on cardiac surgical procedures, and limited data are available regarding the results of gastrointestinal and oncological surgery.

Some authors have demonstrated that a high BMI is an independent predictor of mortality, while others have argued that the risk from obesity is directly attributable to clustered risk factors such as smoking or diabetes. $^{1} 2^{14-16}$ The largest of these studies included over 80000 patients who underwent coronary bypass and demonstrated that an elevated BMI was an independent predictor of morbidity and mortality. ${ }^{1}$

A prospective single-institution study included 6336 patients (808 of whom were obese) undergoing various elective general surgical procedures. ${ }^{3}$ Despite higher rates of diabetes, hypertension and coronary disease in

Table 4 Multivariate analyses testing the association between BMI groups and complications controlling for age, neoadjuvant therapy, stage, type of surgery, diabetes, operative time and estimated blood loss

\begin{tabular}{|c|c|c|c|c|c|}
\hline & $\mathbf{N}$ & Crude OR & Adjusted OR & $95 \% \mathrm{Cl}$ & p Value \\
\hline \multicolumn{6}{|c|}{ Any complication } \\
\hline $18.5-25$ & 42 & - & - & - & - \\
\hline $25-30$ & 63 & 1.3 & 1.7 & 0.96 to 2.96 & 0.069 \\
\hline$>30$ & 61 & 1.3 & 1.3 & 0.74 to 2.35 & 0.342 \\
\hline \multicolumn{6}{|c|}{ Anastomotic leak } \\
\hline $18.5-25$ & 10 & - & - & - & - \\
\hline $25-30$ & 5 & 0.5 & 0.4 & 0.13 to 1.27 & 0.120 \\
\hline$>30$ & 12 & 0.9 & 0.8 & 0.30 to 2.04 & 0.613 \\
\hline \multicolumn{6}{|c|}{ Surgical site infection } \\
\hline $18.5-25$ & 4 & - & - & - & - \\
\hline $25-30$ & 7 & 1.6 & 1.5 & 0.39 to 5.78 & 0.558 \\
\hline$>30$ & 10 & 1.9 & 1.7 & 0.45 to 6.11 & 0.447 \\
\hline \multicolumn{6}{|l|}{ Pneumonia } \\
\hline $18.5-25$ & 16 & - & - & - & - \\
\hline $25-30$ & 18 & 0.7 & 1.0 & 0.48 to 2.25 & 0.935 \\
\hline$>30$ & 19 & 0.9 & 1.0 & 0.43 to 2.10 & 0.900 \\
\hline
\end{tabular}


obese patients, the morbidity rates among patients with BMI $<30$ and patients with BMI $\geq 30$ were very similar ( $16.3 \%$ vs $15.1 \%, \mathrm{p}=0.26)$, with the exception of an increased incidence of surgical site infection after open surgery in obese patients $(4 \%$ vs $3 \%, \mathrm{p}=0.03){ }^{3}$ Furthermore, in a multivariate regression analysis, obesity was not a risk factor for the development of postoperative complications. However, this study had several limitations, such as the exclusion of patients undergoing thoracic procedures, significantly more laparoscopic procedures conducted among non-obese patients and no details given regarding outcomes according to the specific operations; it was thus difficult to draw conclusions regarding the association between obesity and outcomes after gastrointestinal oncological surgery. ${ }^{3}$

Fujitani et al from MD Anderson reported that BMI $\geq 26$ was an independent risk factor for the development of perioperative complications in 71 patients undergoing surgery for adenocarcinoma of stomach and gastrooesophageal junction (relative risk 4.08, $\mathrm{p}=0.038$ ). ${ }^{17}$ A more recent study from Europe found that BMI $>25 \mathrm{~kg} / \mathrm{m}^{2}$ was not associated with worse outcomes in 215 patients undergoing oesophagectomy for cancer; specifically, there were no differences in operative times (median 280 min in both normal or high BMI), morbidity ( $49 \%$ vs $53 \%, \mathrm{p}=0.4)$, mortality $(8.3 \%$ vs $3.4 \%, \mathrm{p}=0.1)$ and median number of harvested lymph node (14 vs 11 , $\mathrm{p}=0.054) .{ }^{18}$ Two recent studies by Blom et $a l^{19}$ and Grotenhius $e t a l^{20}$ have both demonstrated that patients with elevated BMI do not experience an increase in operative outcomes or oncological outcomes. However, Blom and colleagues did demonstrate an increase in anastomotic leaks in the obese population, a finding which we did not corroborate.

Scipione et al compared 133 profoundly obese patients (BMI $\geq 35 \mathrm{~kg} / \mathrm{m}^{2}$ ) undergoing transhiatal oesophagectomy for either benign or malignant diseases with a matched randomly selected, non-obese (BMI 18.5 to $30 \mathrm{~kg} / \mathrm{m}^{2}$ ) control population of 133 patients. The two populations had similar incidence of diabetes, hypertension, coronary artery diseases and American Society of Anesthesiologists (ASA) score. The cancer patients were also similar with regard to stage and administration of neo-adjuvant therapy. Profoundly obese patients had significantly higher intraoperative blood loss (361 vs $492 \mathrm{ml}$, $\mathrm{p}=0.001$ ), greater need for partial sternotomy to gain access to the cervical oesophagus ( 3 vs $18, \mathrm{p}=0.001$ ) and higher frequency of recurrent laryngeal nerve injury $(0 \mathrm{vs}$ $6, \mathrm{p}=0.04)$. There were no significant differences in the occurrence of chylothorax, wound infection, anastomotic dehiscence or length of hospitalisation. ${ }^{21}$

Healy et al reported on perioperative complications after surgery for oesophageal and oesophagogastric adenocarcinoma in 150 patients, 36 of which had BMI higher than $30 \mathrm{~kg} / \mathrm{m}^{2}$. Both univariate and regression analyses demonstrated that obese patients had higher incidence of respiratory complications ( $38 \%$ vs $58 \%, \mathrm{p}=0.37$ ), pleural effusions $(24 \%$ vs $42 \%, \mathrm{p}=0.032)$ and anastomotic leaks $(2 \%$ vs
$14 \%, \mathrm{p}=0.009)$. In their study, obese patients were more likely to receive multimodality therapy $(50 \%$ vs $67 \%$, $\mathrm{p}=0.18$ ). Number of nodes included in the specimen was lower for obese patients ( 15 vs $10, \mathrm{p}=0.008$ ); however, there was no significant difference in those patients with positive nodes $(61 \%$ vs $53 \%$, $\mathrm{p}=0.08) .{ }^{22}$

In our study, we found that $36.7 \%$ and $34.6 \%$ of our patients had BMI greater than 25 and greater than $30 \mathrm{~kg} / \mathrm{m}^{2}$, respectively. While obese patients were found to have a similar stage at presentation, they were as likely to receive multimodality treatment preoperatively, as their non-obese counterparts, an opposite finding to Healy's study.

Normal-weight, overweight and obese patients had the same likelihood of receiving a R0 resection, and nodal harvest did not differ among groups $(\mathrm{p}=0.8$ and $\mathrm{p}=0.72$ ). Currently, there is debate on what should be the minimal number of harvested lymph nodes during oesophagectomy and what impact this has on survival. The number of harvested lymph nodes in our experience was lower following neoadjuvant treatment. Considering the majority of patients in each cohort that received chemoradiation, this could explain the lower lymph node harvest. Additionally, 94 (23.3\%) of patients underwent a transhiatal resection which could also contribute to lower lymph node yield. Interestingly, the average number of lymph nodes included in the specimen did increase significantly following the implementation of routine fat-clearing techniques by our pathologist in 2007 and robotic and total minimally invasive techniques by our surgeons in $2010(8.87 \pm 5.8$ in $1995-2006$ vs $14.1 \pm 7.8$ in 2007-2010, and $20.4 \pm 9.4$ in 2010-present $\mathrm{p}<0.0005)$. At any rate, it is conceivable that by increasing the number of harvested nodes, a difference between groups could become evident, a concept supported by other studies. ${ }^{17}{ }^{21}$ However, we have previously demonstrated that increasing numbers of lymph nodes harvested at oesophagectomy did not improve survival or the incidence of positive lymph nodes when stratified by $<8,9-12,13-20$ or $>20$ nodes $(\mathrm{p}=0.18)$, a finding corroborated by other authors. ${ }^{23} 24$

In our experience, the operative time and the amount of blood loss in obese patients were similar to those observed in normal-weight patients; this observation seems to contradict the perception that an oesophagectomy is technically more demanding in obese patients. Despite the increased frequency of diabetes, obesity did not increase the perioperative morbidity or mortality in patients undergoing oesophageal resection for adenocarcinoma. Concerns that obese patients would have a higher incidence of surgical site infections, pneumonias, venous thromboembolisms or anastomotic leaks could not be verified.

Our study has a few limitations that need to be acknowledged. First, we used weight prior to surgery in our BMI calculation which did not take into account malnutrition and weight loss observed in patients who received neoadjuvant treatment. Confounding factors could have been introduced by those patients with a 
high BMI prior to neoadjuvant treatment that lost enough weight to be classified in a lower-weight category at the time of surgery. Second, few patients, 20 (10.7\%), in our study had BMI $>40 \mathrm{~kg} / \mathrm{m}^{2}$. As mentioned earlier, previous research has suggested that the number of complications rises significantly in patients with extreme obesity. ${ }^{16}$ Since very few of these patients were included, our results should not be generalised to patients in extreme obesity class. Third, this study is based on the experiences of high volume oesophageal surgeons, and the overall rates of intraoperative and postoperative complications are quite low. Therefore, the number of events in patients who were obese and patients of normal weight were too small to adequately assess the differences between the two groups.

\section{CONCLUSIONS}

Our study demonstrates that patients with an elevated BMI and oesophageal adenocarcinoma do not experience an increase in postoperative complications after an oesophagectomy as stated in previous reports. There appears to be a discrepancy in the surgeons' perceptions that operating on obese patients is technically challenging and leads to worse outcomes and the results we have elucidated at our institution. In our data, obesity did not impact the morbidity and mortality associated with oesophagectomy. Furthermore, BMI did not influence the number of harvested lymph-nodes or rates of R0 resections for patients with oesophageal adenocarcinoma. In summary, it is our experience that oesophagectomies can be performed safely and efficiently in overweight and obese patients without increased risk for postoperative complications or compromising oncological outcome.

Contributors MM, JW, RS, SH, KA, RCK and KLM have all reviewed the manuscript and contributed equally in the editing and preparation process.

Funding This research received no specific grant from any funding agency in the public, commercial or not-for-profit sectors.

Competing interests None.

Ethics approval IRB.

Provenance and peer review Not commissioned; externally peer reviewed.

Data sharing statement No additional data are available.

\section{REFERENCES}

1. Wagner BD, Grunwald GK, Rumsfeld JS, et al. Relationship of body mass index with outcomes after coronary artery bypass graft surgery. Ann Thorac Surg 2007;84:10-16.

2. Reeves BC, Ascione R, Chamberlain $\mathrm{MH}$, et al. Effect of body mass index on early outcomes in patients undergoing coronary artery bypass surgery. J Am Coll Cardiol 2003;42:668-76.
3. Dindo $\mathrm{D}$, Muller MK, Weber M, et al. Obesity in general elective surgery. Lancet 2003;361:2032-5.

4. Charlson M, Pompei P, Ales K, et al. A new method of classifying prognostic comorbidity in longitudinal studies: development and validation. J Chronic Dis 1987;40:373-83.

5. Oken M, Creech R, Tormey D, et al. Toxicity and response criteria of the Eastern Cooperative Oncology Group. Am J Clin Oncol 1982;5:649-55.

6. Obesity-preventing and managing the global epidemic. Report of a WHO consultation on obesity. Geneva: World Health Organization, 1997 June, 2007.

7. Moulton MJ, Creswell LL, Mackey ME, et al. Obesity is not a risk factor for significant adverse outcomes after cardiac surgery. Circulation 1996;94(Suppl 9):Il87-92.

8. Shapiro M, Munoz A, Tager IB, et al. Risk factors for infection at the operative site after abdominal or vaginal hysterectomy. $N$ Engl $\mathrm{J}$ Med 1982;307:1661-6.

9. Chapman GW Jr., Mailhes JB, Thompson HE. Morbidity in obese and nonobese patients following gynecologic surgery for cancer. J Natl Med Assoc 1988;80:417-20.

10. Spicer DD, Schaper LA, Pomeroy DL, et al. Cementless cup fixation in total hip arthroplasty after 5-8 years. Int Orthop 2001; 25:286-9.

11. Pasulka PS, Bistrian BR, Benotti PN, et al. The risks of surgery in obese patients. Ann Intern Med 1986;104:540-6.

12. Brandt M, Harder K, Walluscheck KP, et al. Severe obesity does not adversely affect perioperative mortality and morbidity in coronary artery bypass surgery. Eur J Cardiothorac Surg 2001; 19:662-6.

13. Engelman DT, Adams DH, Byrne JG, et al. Impact of body mass index and albumin on morbidity and mortality after cardiac surgery J Thorac Cardiovasc Surg 1999;118:866-73.

14. Jin R, Grunkemeier GL, Furnary AP, et al. Is obesity a risk factor for mortality in coronary artery bypass surgery? Circulation 2005;111:3359-65.

15. Pan W, Hindler K, Lee VV, et al. Obesity in diabetic patients undergoing coronary artery bypass graft surgery is associated with increased postoperative morbidity. Anesthesiology 2006; 104:441-7.

16. Filardo G, Hamilton C, Hamman B, et al. Categorizing BMI may lead to biased results in studies investigating in-hospital mortality after isolated CABG. J Clin Epidemiol 2007;60:1132-9.

17. Fujitani $\mathrm{K}$, Ajani JA, Crane $\mathrm{CH}$, et al. Impact of induction chemotherapy and preoperative chemoradiotherapy on operative morbidity and mortality in patients with locoregional adenocarcinoma of the stomach or gastroesophageal junction. Ann Surg Oncol 2007;14:2010-17.

18. Morgan MA, Lewis WG, Hopper AN, et al. Prognostic significance of body mass indices for patients undergoing esophagectomy for cancer. Dis Esophagus 2007;20:29-35.

19. Blom RL, Lagarde SM, Klinkenbijl JH, et al. A high body mass index in esophageal cancer patients does not influence postoperative outcome or long-term survival. Ann Surg Oncol 2012;19:766-71.

20. Grotenhuis BA, Wijnhoven BPL, Hötte GJ, et al. Prognostic value of body mass index on short-term and long-term outcome after resection of esophageal cancer. World J Surg 2010;34:2621-7.

21. Scipione $C N$, Chang $A C$, Pickens A, et al. Transhiatal esophagectomy in the profoundly obese: implications and experience. Ann Thorac Surg 2007;84:376-82; discussion 83.

22. Healy LA, Ryan AM, Gopinath B, et al. Impact of obesity on outcomes in the management of localized adenocarcinoma of the esophagus and esophagogastric junction. $J$ Thorac Cardiovasc Surg 2007;134:1284-91.

23. Almhanna K, Weber JM, Shridhar R, et al. Effect of lymphadenectomy on survival in patients with esophageal cancer. ASCO Meeting Abstr 2012;30(Suppl 4):65.

24. Hsu PK, Wang BY, Chou TY, et al. The total number of resected lymph node is not a prognostic factor for recurrence in esophageal squamous cell carcinoma patients undergone transthoracic esophagectomy. J Surg Oncol 2011;103:416-20. 